\title{
Stress cardiac magnetic resonance imaging effectively reclassifies risk in patients with known or suspected stable coronary artery disease
}

Jiazuo H Feng ${ }^{*}$, Ravi Shah, Bobby Heydari, Venkatesh L Murthy, Siddique Abbasi, Tomas G Neilan, Ron ABlankstein , Marcelo Di Carli, Michael Jerosch-Herold, Raymond Y Kwong

From 16th Annual SCMR Scientific Sessions

San Francisco, CA, USA. 31 January - 3 February 2013

\section{Background}

A recent large-scale clinical trial has indicated that an initial invasive strategy does not improve cardiac outcomes beyond optimized medical therapy in patients with stable coronary artery disease (CAD). Therefore, novel methods to stratify at-risk patients may refine therapeutic decisions and improve outcomes. We sought to test the hypothesis that stress cardiac magnetic resonance (CMR) imaging effectively prognosticates and reclassifies patient risk in a consecutive clinical cohort of patients with known or suspected CAD across a spectrum of guideline-determined risk categories.

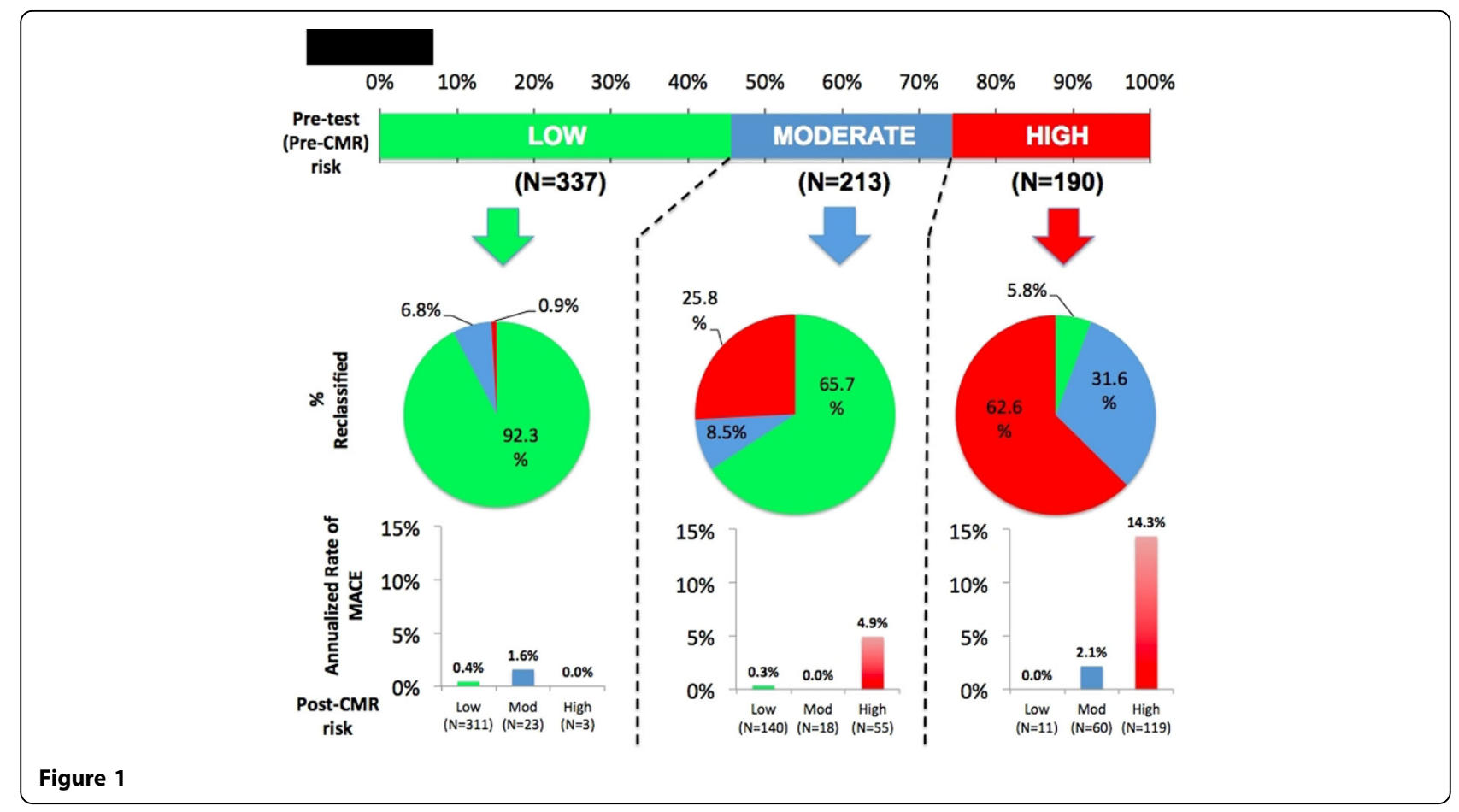

Brigham and Women's Hospital, Boston, MA, USA

(c) 2013 Feng et al; licensee BioMed Central Ltd. This is an Open Access article distributed under the terms of the Creative Commons 

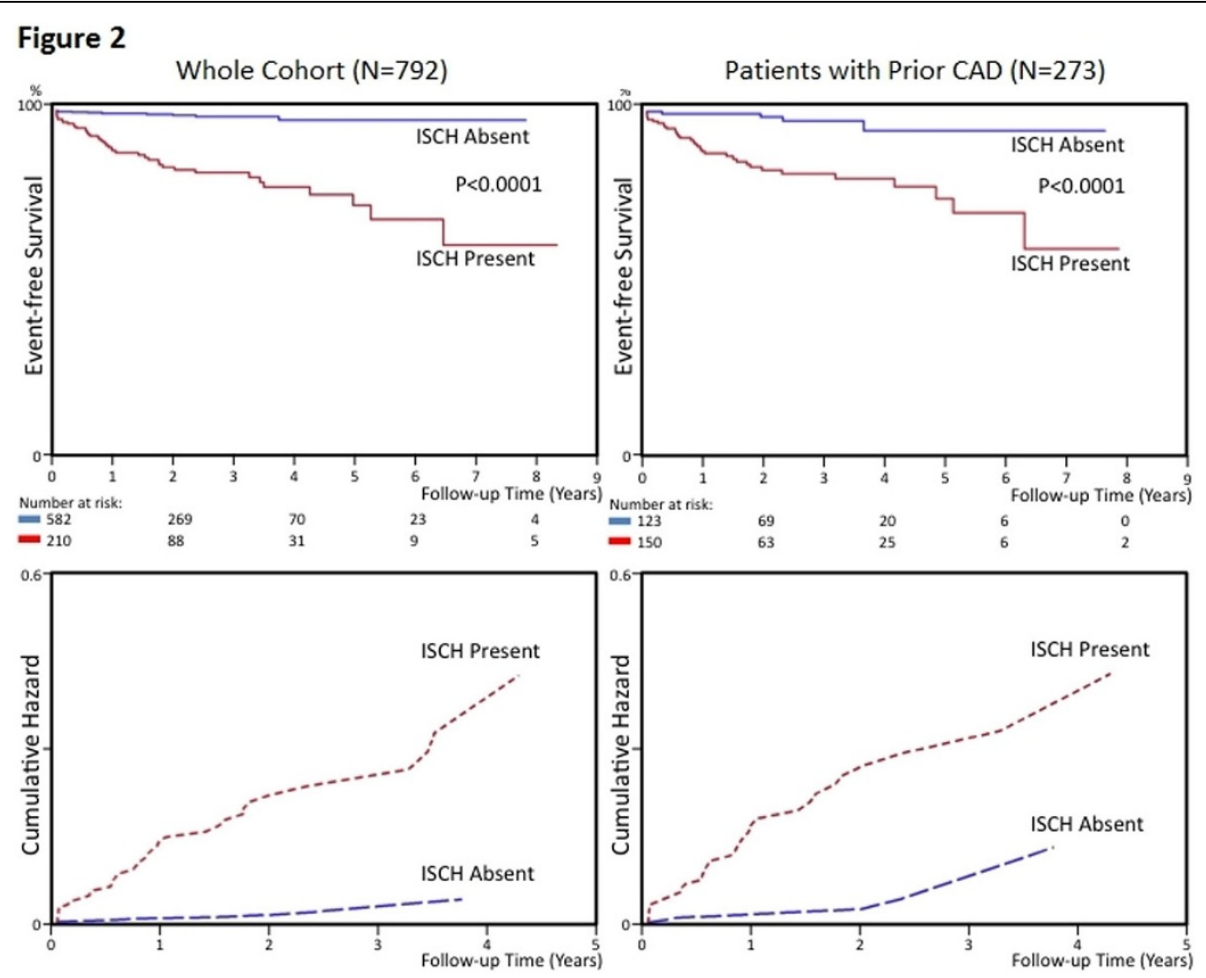

Figure 2 Kaplan-Meier MACE-free survival curves for the whole cohort (A) and patients with prior CAD (B). Follow-up period was truncated to 8 years. The bottom graphs ( $C$ and $D$ ) displayed the corresponding cumulative hazard function (bottom panels) for illustration of rates of MACE accumulation in these respective patient groups during the first 5 years after stress CMR assessment. P-value was derived using the log-rank test. Abbreviations: ISCH = inducible ischemia by stress CMR.

\section{Methods}

In a prospective observational study of 815 consecutive patients clinically referred for stress CMR between 2001-2011, we studied the association of inducible ischemia on a composite of cardiac mortality and acute non-fatal myocardial infarction (MACE). We constructed Cox regression models to measure the independent and incremental association of inducible ischemia with our composite outcome beyond traditional markers of risk (including prior CAD). In addition, we quantified net reclassification improvement across guideline-based 3 -year risk categories of MACE: low $(<3 \%)$, moderate (3-9\%), and high (>9\%) by inducible ischemia by CMR, incremental to clinical risk models.

\section{Results}

Inducible ischemia was the strongest predictor of MACE in the overall cohort and in patients with prior CAD (hazard ratios 15.66 and 8.18 , respectively; $\mathrm{P}<0.0001$ ). Absence of inducible ischemia was associated with low annual rates of MACE and cardiac death (whole cohort, $0.6 \%$ and $0.4 \%$; prior CAD, $1.3 \%$ and $0.6 \%$, respectively). Addition of inducible ischemia to the best clinical risk model (age and prior CAD adjusted) improved discrimination of MACE (C-statistic 0.81 to $0.86 ; \mathrm{P}<0.0001)$.
Inducible ischemia reclassified $91.5 \%$ of patients at moderate pre-test risk ( $65.7 \%$ to low risk; $25.8 \%$ to high risk), with corresponding changes in annual event rates (posttest low risk, 0.3\%/year; post-test high risk, 4.9\%/year). Categorical net reclassification index was 0.229 (95\% 0.063-0.391). For patients with prior CAD, inducible ischemia reclassified $44 \%$ of patients at moderate pre-test risk and $37 \%$ at high pre-test risk to lower post-test risk, with a low annual rate of MACE (1.2\%/year in both groups).

\section{Conclusions}

The presence and extent of inducible ischemia by stress CMR effectively reclassifies patient risk beyond standard clinical risk factors, specifically in patients at moderateto-high pre-test risk and in patients with prior CAD.

\section{Funding}

Dr. Shah is supported by an American Heart Association Post-Doctoral Fellowship Award (11POST000002) and a training grant from the Heart Failure National Institutes of Health Clinical Research Network (U01-HL084877). Dr. Heydari is supported by a Clinical Fellowship Award from the Alberta Heritage Foundation for Medical Research. Dr. Murthy is supported by National Institutes of Health training grant T32-HL094301. Dr. Kwong is supported by 
a National Institutes of Health grant R01-HL091157 and a research grant from Astellas Pharmaceuticals.

Published: 30 January 2013

doi:10.1186/1532-429X-15-S1-P186

Cite this article as: Feng et al: Stress cardiac magnetic resonance

imaging effectively reclassifies risk in patients with known or suspected

stable coronary artery disease. Journal of Cardiovascular Magnetic

Resonance 2013 15(Suppl 1):P186.

Submit your next manuscript to BioMed Central and take full advantage of:

- Convenient online submission

- Thorough peer review

- No space constraints or color figure charges

- Immediate publication on acceptance

- Inclusion in PubMed, CAS, Scopus and Google Scholar

- Research which is freely available for redistribution

Submit your manuscript at www.biomedcentral.com/submit 